\title{
TRABAJO PRÁCTICO: recurso que propicia el aprendizaje significativo sobre diversidad y ecología microbiana en estudiantes de grado cuarto $\left(4^{\circ}\right)$ del colegio Champagnat de Bogotá.
}

\section{PRACTICAL WORK: A resource that promotes meaningful learning about diversity and microbial ecology in fourth grade students (4 th) Champagnat School from Bogota}

Por: Juan Carlos Rozo González ${ }^{1}$

Recibido: 28-03-2011

Aceptado: 28-06-2011

\section{Resumen}

Se implementó una propuesta dinámica e innovadora como lo es la elaboración de trabajos prácticos para la enseñanza de la microbiología en primaria con estudiantes de grado cuarto $\left(4^{\circ}\right)$ del colegio Champagnat de Bogotá. Este trabajo pretende establecer las actividades como recursos que propician el aprendizaje significativo acerca de diversidad y ecología microbiana. De igual manera, se realizan con el fin de que los estudiantes reconozcan la importancia y las interacciones de los microorganismos con el ambiente.

En este artículo se mostrarán diferentes actividades prácticas como la elaboración de talleres y carreras de observación, las cuales permitieron establecer categorías de análisis respecto a la interpretación que los estudiantes tienen acerca de los microorganismos, generando en ellos habilidades actitudinales, conceptuales y procedimentales, orientándolos al trabajo científico e investigativo.

Palabras clave: Trabajos prácticos, aprendizaje significativo, diversidad, ecología microbiana.

\section{Abstract}

A dynamic and innovative proposal was implemented: the development of practical works for Microbiology teaching in elementary school, with fourth grade Bogotá Champagnat School students. This paper aims to establish the activities as resources that favour meaningful learning about diversity and microbial ecology. Likewise, these activities were carried out so that the students can recognize the importance and the interactions of the microorganisms with the environment.

In this article different practical activities will be shown such as the development of workshops and observation races which allowed to establish analysis categories about the interpretation that the students have

\footnotetext{
${ }^{1}$ Estudiante de VIII semestre de Licenciatura en Biología. Universidad Pedagógica Nacional. Línea de investigación biotecnología y educación, Bogotá, Colombia 2010. E-mail: rustu90_14@hotmail.com
} 
about microorganisms, generating in them attitudinal, conceptual and procedural skills, guiding them to the scientific and researchable work.

Keywords: Practical work, significant learning, diversity, microbial ecology

\section{INTRODUCCIÓN}

La enseñanza de las ciencias ha sido tema de discusión por varias corrientes de pensamiento como lo es el constructivismo, conductismo y el innatismo. A su vez ha generado un gran número de investigaciones, donde se busca analizar y estudiar los procesos de enseñanza-aprendizaje en ciencias para mejorar la calidad de la educación no sólo a nivel local sino a nivel mundial. En esta medida los trabajos prácticos pueden ser entendidos como las actividades de enseñanza de las ciencias en las que los alumnos han de utilizar determinados procedimientos para resolverlas. Estos procedimientos están relacionados con el trabajo de laboratorio o de campo, pero en un sentido más amplio pueden englobar la resolución de problemas científicos o tecnológicos de diferentes características. Del Carmen, L. (2000).De la misma manera, pueden aportar para que se dé este mejoramiento, pero todo depende de quién piensa, ejecuta y reflexiona esta labor, es decir, el maestro, quien tiene la responsabilidad de utilizar de forma adecuada este recurso y no permitir que este trabajo se convierta solamente en la creación de actividades sin tener objetivos y fundamentos tanto teóricos como epistemológicos claros; si es así, terminaría siendo un ejercicio de entretenimiento para el estudiante donde posiblemente no haya una construcción de conocimiento (Fonseca, G.,2010).

En relación con la enseñanza de la microbiología, se puede decir que los trabajos prácticos van ligados a la microbiología ya que permiten realizar trabajos de campo, y de laboratorio, donde necesitan de estas actividades para desarrollar en los estudiantes habilidades conceptuales, procedimentales y actitudinales. También le permite al sujeto tener una relación directa con los microorganismos; donde los puede observar, dibujar, tomar un registro fotográfico y así mismo llevar un seguimiento del ciclo de vida de estos organismos; lo que llevaría al estudiante a la indagación, planteamiento de hipótesis, elaboración de experimentos y pensar sobre los fenómenos que está observando; de esta manera el sujeto construye un conocimiento a partir de los resultados obtenidos; en este sentido se recomienda enseñar y hacer ciencia a través de la microbiología en la escuela.

En este artículo se presentan una serie de trabajos prácticos con el fin de establecerlos como una propuesta de recursos que propician el aprendizaje significativo sobre la diversidad y ecología microbiana, dirigido a los estudiantes de grado cuarto (4⿳⺈) del colegio Champagnat de Bogotá. Igualmente, se pretende orientar a los estudiantes hacia el trabajo científico e investigativo por medio de dichas actividades relacionadas con la microbiología. Por último, establecer las categorías de análisis o de interpretación que tienen los niños sobre los microorganismos con el fin de utilizarlos como referentes conceptuales a la hora de enseñar microbiología en primaria específicamente en grado cuarto. Además, posibilita al docente conocer las diferentes posturas que tienen los estudiantes sobre diversidad y ecología microbiana 
mediante la elaboración de los trabajos prácticos "video todo sobre las bacterias" y la carrera de observación "buscando el mundo perdido".

A partir de lo expuesto anteriormente y a la contextualización de la institución así como a la revisión de los estándares básicos de la educación en Colombia propuesta por el Ministerio de Educación Nacional (MEN) frente a la enseñanza de la microbiología en primaria, se realizó el siguiente planteamiento: ¿Por qué es importante establecer el trabajo práctico como recurso que propicia el aprendizaje significativo de diversidad y ecología microbiana en los estudiantes de grado cuarto $\left(4^{\circ}\right)$ del colegio Champagnat de Bogotá? A partir de esta pregunta se tomaron conceptos que estructuran y fundamentan teóricamente la investigación, los cuales fueron trabajados con la debida trasposición didáctica para niños de cuarto de primaria $\left(4^{\circ}\right)$ en esta medida los conceptos estructurantes fueron los siguientes: trabajos prácticos, aprendizaje significativo, clasificación bacteriana, ecología microbiana, estructura y dinámica de las poblaciones microbianas. La trasposición didáctica es un proceso que se llevó a cabo mediante la elaboración de trabajos prácticos como talleres, video introductorio sobre las bacterias y la carrera de observación "Buscando el mundo perdido" los cuales le permiten al estudiante recibir los conceptos no de forma arbitraria sino que por medio de la experiencia y lo brindado por el docente, establece un paralelo forjando así una construcción de un nuevo conocimiento.

\section{TRABAJOS PRÁCTICOS Y APRENDIZAJE SIGNIFICATIVO}

Los Trabajos Prácticos (T.P) son entendidos como aquellos trabajos realizados por los estudiantes, desarrollados en clase y en prácticas de campo, que pueden o no involucrar un grado de interacción con el profesor; permiten desarrollar destrezas científicas tales como la investigación y la manipulación (Miguens, D \& Garrett, R., 1991), Existen varios tipos de trabajos prácticos tales como investigaciones, laboratorios explicativos y demostraciones. Todo con el fin de que el estudiante se involucre con el trabajo científico y así mismo pueda solucionar problemas. (Barberá y Valdez, 1996) sostienen que los trabajos prácticos son una estrategia educativa útil para el estudiante con el fin de conseguir cualquier objetivo educativo planteado, estos trabajos hacen que aumenten su conocimiento tácito y su confianza para resolver los sucesos y eventos que ocurren en la naturaleza desarrollando su competencia técnica, de igual manera proporciona la comprensión de los principios teóricos de las disciplinas y la recopilación de hechos y datos.

Los trabajos prácticos hacen referencia a las actividades de enseñanza de las ciencias en las que los alumnos han de utilizar determinados procedimientos para resolverlas. Estos procedimientos están relacionados con el trabajo de laboratorio o de campo, pero en un sentido más amplio pueden englobar la resolución de problemas científicos o tecnológicos de diferentes características. Del Carmen, L (2000) Los T.P tienen características como: son realizadas por el alumno aunque con un grado variable de participación en su diseño y ejecución implican el uso de procedimientos científicos, diferentes características (observación, formulación de hipótesis, realización de experimentos, técnicas manipulativas y elaboración de conclusiones). 
Los trabajos prácticos se constituyen en una de las actividades más importantes en la enseñanza de las ciencias por permitir una multiplicidad de objetivos: la familiarización, observación e interpretación de los fenómenos que son objeto de estudio en las clases de ciencias, el contraste de hipótesis en los procesos de modelización de la ciencia escolar, el aprendizaje del manejo y de instrumentos y técnicas de laboratorio y de campo, la aplicación de estrategias de investigación para la resolución de problemas teóricos y prácticos y en definitiva, la comprensión procedimental de la ciencia (Caamaño, L 2003) Siguiendo a Caamaño, L (2003), estos trabajos pueden ser catalogados en: experiencias, ejercicios prácticos y experimentos ilustrativos.

En el contexto actual y nacional Castro, M \& Valbuena, E (2007) plantean la experimentación biológica, las narraciones históricas, el trabajo de campo, la observación y la modelización, como principales formas de producir conocimiento biológico en los contextos científico y escolar y desde allí, la necesidad de configurar un espacio de reflexión acerca de un tema específico, en este caso la diversidad y ecología microbiana.

El aprendizaje significativo para Gutiérrez, R (1987), es la adquisición de grandes cuerpos de conocimiento integrados, coherentes, estables, que tienen sentido para los alumnos. Para que el aprendizaje se dé el alumno debe tener una disponibilidad y la información debe tener un material de significancia lógica para el estudiante. La esencia del proceso del aprendizaje significativo reside en que ideas expresadas simbólicamente son relacionadas de modo no arbitrario, sino sustancial (no al pie de la letra) con lo que el alumno ya sabe, señaladamente con algún aspecto esencial de su estructura de conocimientos (por ejemplo, una imagen, un símbolo ya con significado, un contexto, una proposición.

Para que realmente sea significativo el aprendizaje, éste debe reunir varias condiciones: la nueva información debe relacionarse de modo no arbitrario y sustancial con lo que el alumno ya sabe, dependiendo también a su disposición (motivación y actitud) del sujeto por aprender, así como de la naturaleza de los materiales o contenidos de aprendizaje. Durante el aprendizaje significativo el alumno relaciona de manera no arbitraria y sustancial la nueva información con los conocimientos y experiencias previas y familiares, que ya posee en su estructura de conocimientos o cognitiva. Este aprendizaje puede promoverse mediante estrategias apropiadas, por ejemplo, los organizadores convenciones anticipados y los mapas conceptuales, (Díaz, F, 1999).

\section{INTERACCIONES ENTRE MICROORGANISMOS.}

Campbell, R (1987) dice que los organismos no pueden existir de forma aislada en la naturaleza, es por ello que necesitan relacionarse con otros para poder vivir en un espacio y tiempo determinado; existen dos tipos generales de interacciones: benéficas o sinérgicas entre las que se encuentra el comensalismo y la simbiosis; y las 
antagónicas donde hay un perjuicio de alguna parte de la población dentro de estas últimas relaciones podemos encontrar la competencia, la prefación y el parasitismo.

\subsection{COMENSALISMO}

El organismo se beneficia y el otro no se afecta; La degradación de moléculas complejas es realizada por poblaciones mixtas, una población le ofrece a la otra (comensal) un sustrato más simple. La relación es generalmente casual y se conocen varios tipos de relaciones comensalíticas: a) Modificación del sustrato, b) Liberación de sustancias bióticas, c) Remoción de factores inhibidores, d) Superficies adecuadas para la proliferación de microorganismos comensales e) Provisión de nutrientes, protección o albergue (Campbell. R, 1987).

\subsection{SIMBIOSIS}

Siguiendo a Campbell, R (1987) la simbiosis es el beneficio mutuo con contacto estrecho, casi siempre obligatorio. Los mecanismos involucrados en las asociaciones simbiótikas:

a) Aumento de la velocidad de crecimiento: efecto muy reconocido, el protozoo infectado con su alga específica crece más rápidamente que solo. Se puede apreciar esto por aumento de la población o masa.

b) Estimulación de la actividad metabólica (respiración, etc.)

c) Provisión de fuentes de carbono por la fotosíntesis: las algas en simbiosis en los líquenes o con protozoos o invertebrados acuáticos o con plantas, fotosintetizan en exceso para sus necesidades y satisfacen así los requerimientos de sus asociados.

\subsection{RELACIONES ANTAGONICAS}

En esta tipo de relación según Campbell, R (1987) hay un perjuicio de alguna parte de la población, un tipo de relación de este tipo es la competencia la cual puede ser intraespecífica como interespecífica. La capacidad de un organismo para competir está gobernada por:

a) Alta velocidad de crecimiento. La especie que prolifera más rápido usa los nutrientes limitantes con ventaja para los que son de crecimiento lento.

b) Tolerancia a factores abióticos. Tienen ventajas ecológicas las especies capaces de crecer en condiciones ambientales extremas, sean cuales sean.

c) Capacidad de multiplicarse a bajas concentraciones del nutriente limitante. Es una propiedad que pocas especies poseen. Ejemplo: algas que crecen bien a concentraciones muy bajas de nitratos o fosfatos.

d) Eficiencia en el uso de nutrientes limitantes: son aquellos organismos que con muy poca cantidad de nutrientes asimilables igual pueden sintetizar citoplasma. 


\subsection{PREDACIÓN}

La predación es el ataque directo de una especie sobre otra con muerte de la presa. En esta asociación microbiana el predador se alimenta de un segundo organismo causando frecuentemente la muerte del organismo unicelular o la destrucción de parte o de toda la presa, en organismos pluricelulares. Es una de las más dramáticas asociaciones entre microorganismos en la naturaleza. Campbell, R (1987).

\subsection{PARASITISMO}

En el parasitismo un organismo se alimenta de otro generalmente mayor (hospedante) causando algún daño (desde muy pequeño hasta la muerte). Muy pocos organismos están libres del ataque de parásitos microbianos. La mayoría son parásitos obligados que viven casi toda su existencia de éste modo tomando lo dicho por Campbell, R (1987) pueden ser:

a) Parásitos intracelulares: bacteriófagos, actinófagos

b) Ectoparásitos: se localizan en la parte externa del hospedante, pero es más raro entre microorganismos.

\section{METODOLOGÍA}

El proyecto planteado se desarrollo desde un enfoque investigativo cualitativo. Este enfoque estudia la calidad de las actividades, relaciones, asuntos, medios, materiales o instrumentos en una determinada situación o problema. Torres, C (1998) la investigación cualitativa pretende hacer un análisis exhaustivo y con sumo detalle a un tema en particular que para el caso de este proyecto es el trabajo práctico como recurso que propicia el aprendizaje significativo de diversidad y ecología microbiana con estudiantes de grado cuarto $\left(4^{\circ}\right)$ del colegio Champagnat de Bogotá. La investigación comprendió las siguientes fases:

\section{FASE 1: IDENTIFICACIÓN Y DISEÑO}

En esta fase lo que se hizo fue la identificación del problema a investigar a través la contextualización, en primera instancia se realizó el planteamiento de la situación problema pero estuvo sujeta a cambios por parte del tutor de práctica. Cabe señalar que este trabajo se realizó en el marco de la práctica docente.

También se identificó a los participantes de la investigación, los cuales fueron muestra seleccionada y pequeña, en este caso 32 estudiantes de cuarto de primaria de una institución educativa de la ciudad de Bogotá (colegio Champagnat)

Desde el diseño, el tutor de práctica plateó un borrador de lo que iba a llevar la investigación, la realización de una investigación cualitativa requirió de un desarrollo de trabajo exhaustivo y con sumo detalle de lo hecho por el investigador, en este sentido este tipo de trabajo permitió al tutor identificar los avances y dificultades que 
haya tenido el investigador durante su trabajo. La estructura del borrador de trabajo fue el siguiente: contextualización, selección de la temática, objetivos, situación problema, justificación, marco de referencia conceptual, antecedentes, metodología de investigación utilizada, técnicas e instrumentos de recolección, análisis e interpretación de los datos y las actividades a realizar. Esta revisión se hizo y se entregó de forma oportuna al tutor de práctica, de esta manera estuvo sujeta a cambios.

\section{FASE 2: RECOLECCIÓN Y REGISTRO DE INFORMACIÓN}

Dentro de la recolección de datos se emplearon técnicas como la observación, la entrevista, talleres y prácticas de laboratorio basadas en la metodología de Torres, C (1998) en la investigación cualitativa. Por otro lado, teniendo en cuenta que los datos se recogen durante el proceso, se hizo necesario hacer varias actividades para validar o invalidar lo planteado por los estudiantes en un momento determinado.

a) Observación: Consiste en apreciar y percibir con atención ciertos aspectos de la realidad, se basa en un examen atento que se realiza sobre unos sujetos, objetos y hechos. Esto permite recoger o comprobar informaciones desde contactos directos de la realidad, se observaron 9 sesiones de clase de ciencias naturales, cabe señalar que cada clase tenía una duración de cuarenta y cinco minutos, en estas clases se habló sobre los microorganismos, enfocándolos más hacia su diversidad y sus relaciones intraespecíficas e interespecificas en el ambiente.

Desde la observación el trabajo se centró en una observación participante, en la cual el investigador se encontró y relacionó de manera directa con los sujetos de la investigación, este tipo de observación acude a las fuentes primarias y originales del problema estudiado y posibilita la captación de circunstancias y estados de ánimo solo posibles de identificar como experiencias propias, de esta manera se puede saber si el estudiante puede lograr un aprendizaje sobre el tema abordado (diversidad y ecología microbiana)

b) Entrevistas: Es una conversación entre dos o más personas, dirigida por el entrevistador con preguntas y respuestas desde diferentes grados de formalidad. Esta técnica permite recoger informaciones desde opiniones, ideas, críticas sobre temas y situaciones específicas. Las entrevistas realizadas fueron semiestructuradas dirigidas a los docentes encargados de orientar las clases de ciencias naturales dentro del aula y a los mismos estudiantes del grado cuarto $\left(4^{\circ}\right)$.

c) Talleres y salidas de campo: consiste en jornadas de trabajo de un grupo de personas en torno a un tema específico (microorganismos) en el cual se busca producir nuevos aportes a partir de insumos previos como lecturas, videos y exposiciones por parte del docente en formación. Para llevar este registro se tomó una herramienta utilizada por la institución que es la es la cartilla estudiantil. Para la colecta de los microorganismos se tomaron las salidas ecológicas que brinda el colegio, de igual manera se realizaron con el fin de que los estudiantes pudieran 
conocer las relaciones macroscópicas y microscópicas de los organismos y el ambiente.

Las temáticas abordadas en el diseño de las actividades prácticas fueron las siguientes:

a) Habitad de los microorganismos.

b) Implicaciones que tienen los microorganismos para la salud (patógenos y no patógenos).

c) Morfología de los microorganismos.

d) Funciones vitales.

e) Interacciones interespecificas y intraespecíficas.

f) Tipos de microorganismos que habitan en el suelo.

g) Colecta de microorganismos que habitan en el suelo.

h) Organización externa de los seres vivos (individuo, población, comunidad, ecosistema, paisaje, bioma y biosfera).

i) Diversidad biológica (todos los dominios de la naturaleza) y los factores abióticos que se encuentran en el ambiente.

\section{FASE 3: OPERACIONES A TRABAJAR PARA EL ANÁLISIS DE LA INFORMACIÓN}

En la tercera y última fase fue el análisis de la información mediante cuatro categorías las cuales fueron:
a) Categorización y codificación
b) Ordenación y clasificación
c) Establecimiento de relaciones
d) Establecimiento de redes causales y modelos analíticos de síntesis.

\section{RESULTADOS Y ANALISIS}

\section{Trabajo practico video "todo sobre las bacterias"}

En el primer trabajo práctico (T.P) el alumno se enfrentó con el medio audiovisual no con el fin de complementar una explicación teórica realizada por el docente en ejercicio sino que el (T.P) en sí mismo permitiera al estudiante una construcción de saberes y a su vez de un conocimiento; la elaboración de una guía permitió al estudiante una orientación del trabajo, así mismo se pudo conocer cómo el estudiante interpretó analizó y reflexionó lo que pudo comprender acerca de los microorganismos y su ambiente a partir de la solución de dicha guía y de la socialización que se hizo después de haber resuelto la actividad propuesta. Después de haber realizado el (T.P) (video "todo sobre las bacterias") se obtuvieron los siguientes resultados.

El análisis de los resultados respeta las preguntas realizadas en la guía de trabajo y su respectivo orden. A continuación se mostrara en el primer trabajo práctico, diferentes categorías las cuales surgen a partir de las respuestas de los estudiantes frente a las preguntas planteadas, las cuales permiten sintetizar la información colectada por el 
investigador de igual manera ayudan a realizar un marco conceptual frente a lo que saben los estudiantes frente a los microorganismos. Las categorías seleccionadas son: hábitat de los microorganismos, implicaciones que tienen los microorganismos sobre el ser humano, funciones vitales, interacción bacteria-hombre y morfología de los microorganismos.

\section{Categoría 1: Hábitat de los microorganismos}

Pregunta orientadora: ¿En cuál de estas imágenes podremos encontrar microorganismos? Enciérralas en un círculo.

Gráfica 1: Hábitat de los microorganismos. Gráfica que representa los porcentajes de las respuestas dadas por los estudiantes frente a la pregunta orientadora permitiendo establecer la primera categoría de análisis que fue el hábitat de los microorganismos.

\section{Gráfica 1: Hábitat de los microorganismos}

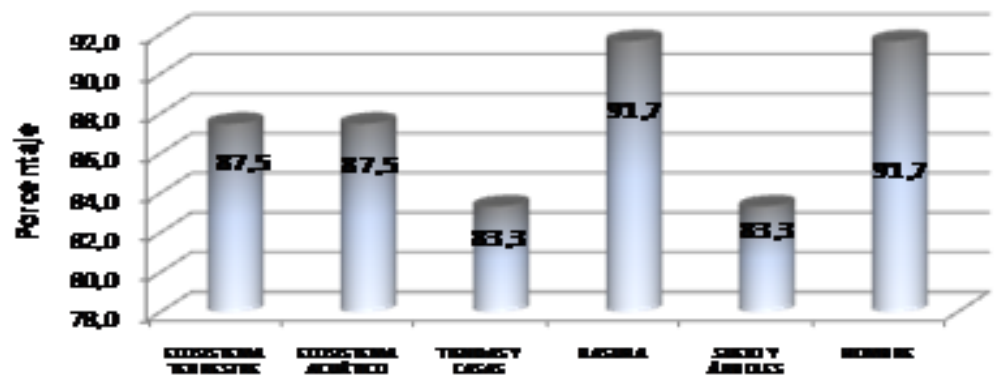

\section{Categoría 1}

Se puede decir que la mayoría de los estudiantes entendieron que estos organismos habitan en cualquier parte de la naturaleza, el $91.7 \%$ de la población muestreada dijo que la mayor parte de los microorganismos habitan en las basuras, dando a entender que éstos organismos están relacionados directamente con cosas nocivas y perjudiciales para la salud. A su vez existe el mismo porcentaje para decir que dichos organismos habitan en el cuerpo humano, esto se debe a que en el video mostrado se hablo mucho sobre las bacterias patógenas y no patógenas, donde se explicaba que así como pueden ayudar también pueden causar la muerte al ser humano. El 87.5\% de los estudiantes afirmaron que los microorganismos también se encuentran en ecosistemas acuáticos y terrestres, en la mayoría de respuestas se observo que para el caso de los ecosistemas terrestres, encerraban en un circulo algunos organismos como por ejemplo la vaca, dando a entender que no solo en la organización externa de los seres vivos de un ecosistema se encuentran dichos organismos sino que también a nivel interno se pueden encontrar. Por otro lado se observo que el $83.3 \%$ respondieron que en lugares comunes como: tiendas, casas, suelo y árboles se pueden encontrar microorganismos, a diferencia de los otros hábitats se evidenció un desconocimiento por parte de los estudiantes sobre el suelo como hábitat de los microorganismos, a la hora de preguntar por el suelo como un espacio habitado por estos organismos ellos realizaron un total rechazo por entender esto ya que ellos decían que dentro de sus clases de ciencias y de lo que conocían popularmente no habían visto y escuchado decir que en este lugar también podían vivir. 
Bio-grafia: Escritos sobre la Biologia y su Enseñanza Vol 4 No6 ISSN 2027-1034. Primer semestre de 2011, Bogotá, Colombia, pp 1-18

Categoría 2: implicaciones que tienen los microorganismos sobre el ser humano.

\begin{tabular}{|c|c|}
\hline NO NOCI & NOC \\
\hline 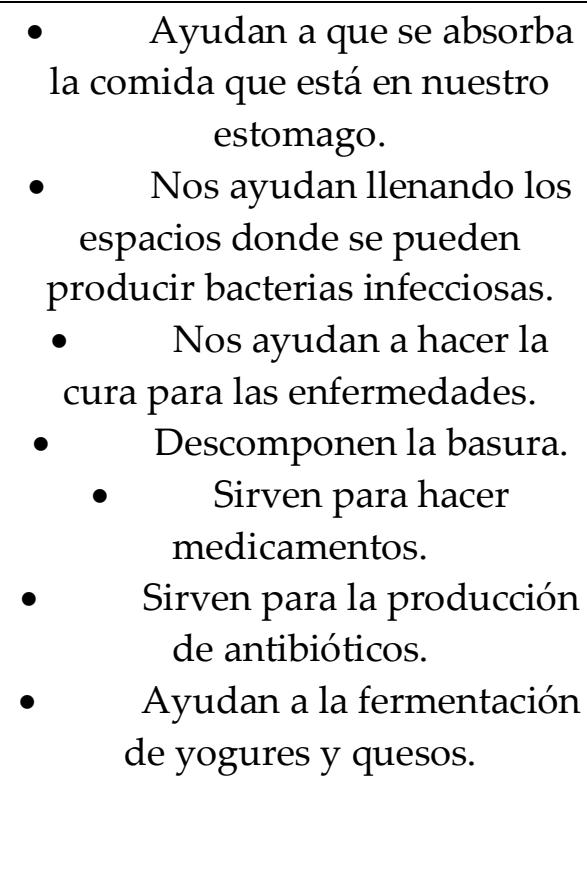 & $\begin{array}{l}\text { - Me enferman, me hacen } \\
\text { actuar raro y me podrían matar. } \\
\text { - } \quad \text { Cuando la bacteria que } \\
\text { produce mi enfermedad se } \\
\text { deposita en la célula. } \\
\text { - Se pueden reproducir } \\
\text { rápido dentro del cuerpo de los } \\
\text { seres vivos y podría enfermar } \\
\text { causando daños físicos. } \\
\text { - } \quad \text { Queman nuestro cuerpo } \\
\text { y hay unos virus que se comen } \\
\text { los tejidos de la piel. } \\
\text { - Contaminan los } \\
\text { - } \quad \text { Perjimentos. } \\
\text { cual explota y suelta una toxina } \\
\text { mortal. }\end{array}$ \\
\hline
\end{tabular}

Esta categoría se realizó con el fin de dar a conocer a los estudiantes que los microorganismos no solo son nocivos y se encuentran relacionados con la contaminación y la higiene como lo hacen ver los medios de comunicación sino que también nos ayudan para regular nuestro cuerpo y también hacen parte del sistema inmune para la defensa de otras bacterias que si podrían causar enfermedades.

Pregunta orientadora: ¿de qué manera los microorganismos perjudican o ayudan a los seres humanos?

A continuación se mostrara una tabla de datos realizada por el docente en ejercicio cuando se realizó la socialización de las respuestas de los estudiantes frente a la pregunta planteada.

Tabla 1: Respuesta de los estudiantes frente a las implicaciones que tienen los microorganismos en el hombre y el ambiente. Esta tabla muestra las respuestas más representativas que tenían los estudiantes frente a la pregunta planteada.

Con respecto a lo anterior se puede decir que la mayoría de los estudiantes lograron identificar las dos implicaciones que tienen los microorganismos (patógeno, no patógeno) en el ser humano, reconocen las bacterias como una ayuda para la digestión del alimento, resaltan la importancia de estos organismos para la realización de antibióticos, estos intervienen en procesos de fermentación, descomposición de basuras y alimentos que llegan a nuestro intestino. En cuanto a las 
respuestas de los estudiantes relacionados con la nocividad, ellos respondieron que estos organismos producen enfermedades que si no se cuidan a tiempo pueden llegar a causar la muerte del organismo, estas bacterias perjudican directamente a la célula la cual hace que se genere una explosión y suelte la enfermedad mortal invadiendo nuestro cuerpo, con lo anterior se puede decir que en los estudiantes hay un error conceptual ya que ven el virus como una bacteria, y más cuando previo a esto se hizo la diferenciación de esta entidad biológica y estos organismos. Además dicen que las bacterias contaminan los alimentos que digerimos, razón por la cual se puede causar una enfermedad, estos organismos se reproducen rápidamente en el cuerpo del ser vivo causando en un tiempo no muy lejano una enfermedad. Cabe resaltar este aspecto ya que los estudiantes que respondieron esto identifican que hay diferentes formas de reproducción en los seres vivos. Entendiendo las bacterias como organismos con reproducción rápida razón por la cual hace que sea el organismos más abulndante en la tierra.

Categoría 3: funciones vitales de los microorganismos.

Esta categoría se realizó para cumplir con los lineamientos curriculares y estándares básicos planteados por el ministerio de educación nacional de Colombia (MEN). Para la enseñanza de las ciencias naturales en grado cuarto. (Características de los seres vivos y funciones vitales) donde se tomó como base estos organismos para mirar si los estudiantes conocen o no estos temas.

Pregunta orientadora: si tú fueras una bacteria ¿Qué funciones necesitarías para vivir?

Para ello se realizó una tabla de datos con relación a las respuestas dadas por los estudiantes; el análisis fue hecho en relación con las siguientes categorías: (nutrición, reproducción, adaptación, homeostasis y metabolismo).

Gráfica 2. Respuesta representada en porcentajes de lo que lograron identificar los estudiantes frente a las funciones vitales de los microorganismos.

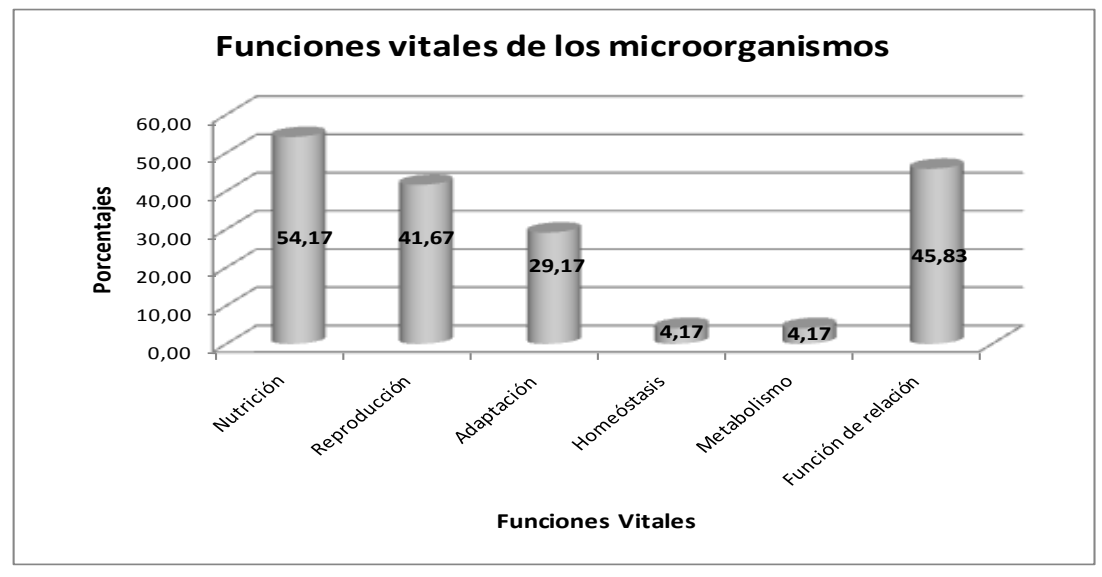

Respecto a la gráfica se puede decir que el mayor porcentaje fue para la función de nutrición, de relación y reproducción con un resultado de: $54.17 \%, 45.83 \%$, 41.67\%, 
esto indica que las funciones que mas resaltan y conocen los estudiantes son las nombradas anteriormente, posiblemente se deba a que en la cotidianidad estas características se manejan de forma más tradicional que por ejemplo la adaptación, la homeostasis y el metabolismo, que son funciones que presentan errores y dificultades conceptuales no solamente por parte de los estudiantes de la institución sino también por parte de la gente que habita en nuestro país.

\section{Categoría 4: interacción bacteria-hombre.}

Pregunta orientadora: ¿Cómo crees que las bacterias se relacionan contigo?

Tabla 2: Interacciones que se dan a nivel bacteria-hombre identificadas por los estudiantes

A continuación se mostrara una tabla que expone las diferentes respuestas de los estudiantes frente a la pregunta planteada.

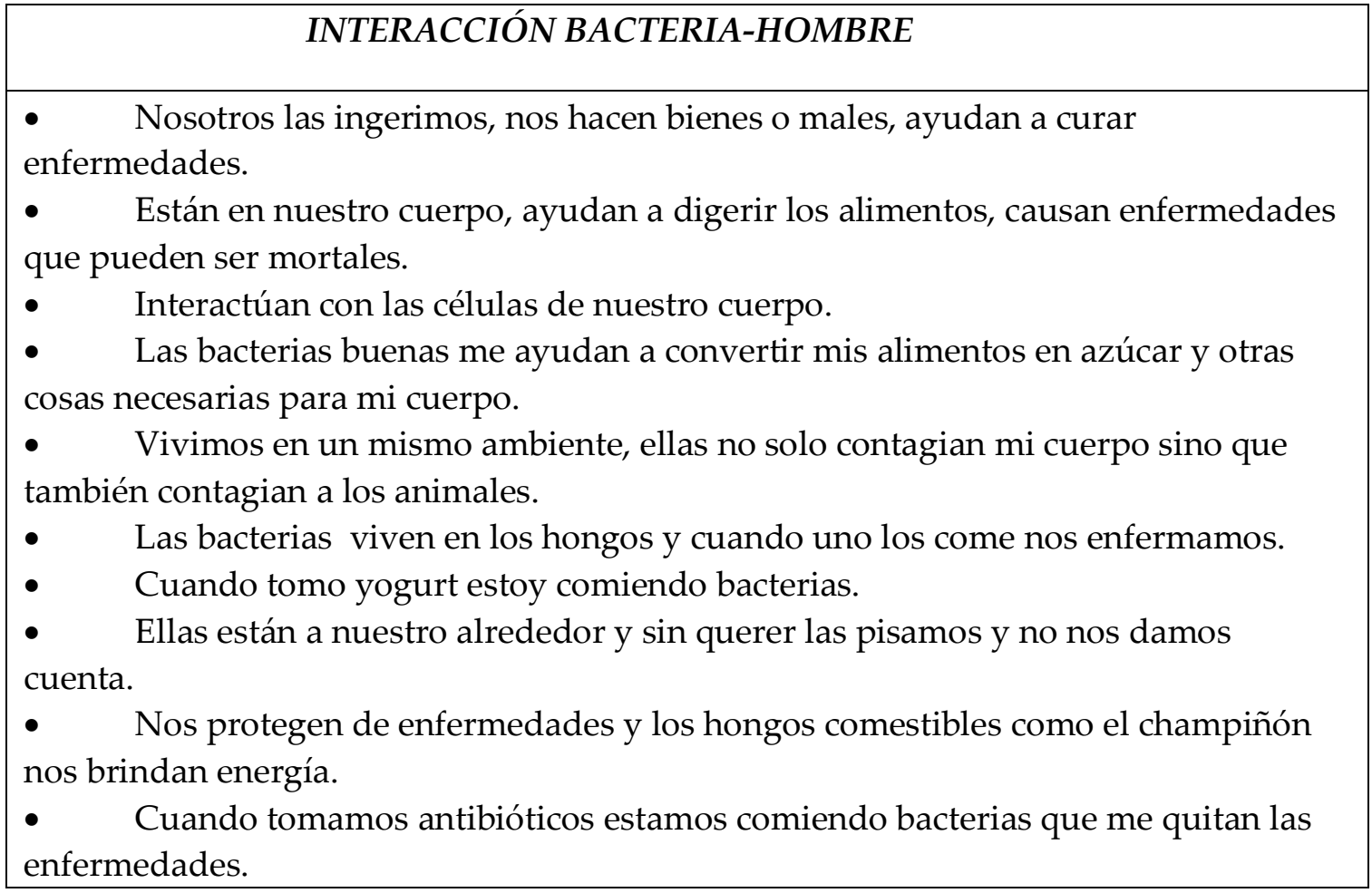

En esta tabla se puede observar que los estudiantes consideran que si tienen una relación directa con las bacterias, se relacionan mediante la fuente de alimentación ya que la mayoría de ellos dice que los microorganismos están en todas partes y que así no se puedan ver a simple vista en muchas ocasiones las tocamos y las comemos por pasa con el yogurt. Por otra parte los estudiantes mencionan que al ser el cuerpo humano un tipo de habitan para las bacterias ellas necesitan de nosotros para poder vivir así como nosotros necesitamos de ellas para poder metabolizar los alimentos, también para reforzar nuestro sistema inmune frente al ataque de microorganismos que si causan enfermedades (flora intestinal), otra relación que se pudo evidenciar en las respuestas de los estudiantes que cuando se consume antibióticos se está también 
haciendo el consumo de bacterias las cuales actúan como un agente que ataca a otros microorganismos que fueron las causantes de la enfermedad. Por otro lado en las respuestas observadas se puede inferir que ellos no solamente ven una interacción entre el hombre y la bacteria sino que también este tipo de organismos interactúan con factores ya sean bióticos o abióticos, las cuales le generan un beneficio o alteración en su regulación.

\section{Categoría 5: Morfología de los microorganismos}

\section{Actividad: Dibuja un microorganismo.}

En esta categoría se puso al estudiante a dibujar un microorganismo, donde se obtuvieron los siguientes resultados:

Ilustración 1 y 2: dibujos de microorganismos hechos por los estudiantes. En estas ilustraciones se muestran los dibujos más representativos realizados por los estudiantes de grado cuarto.
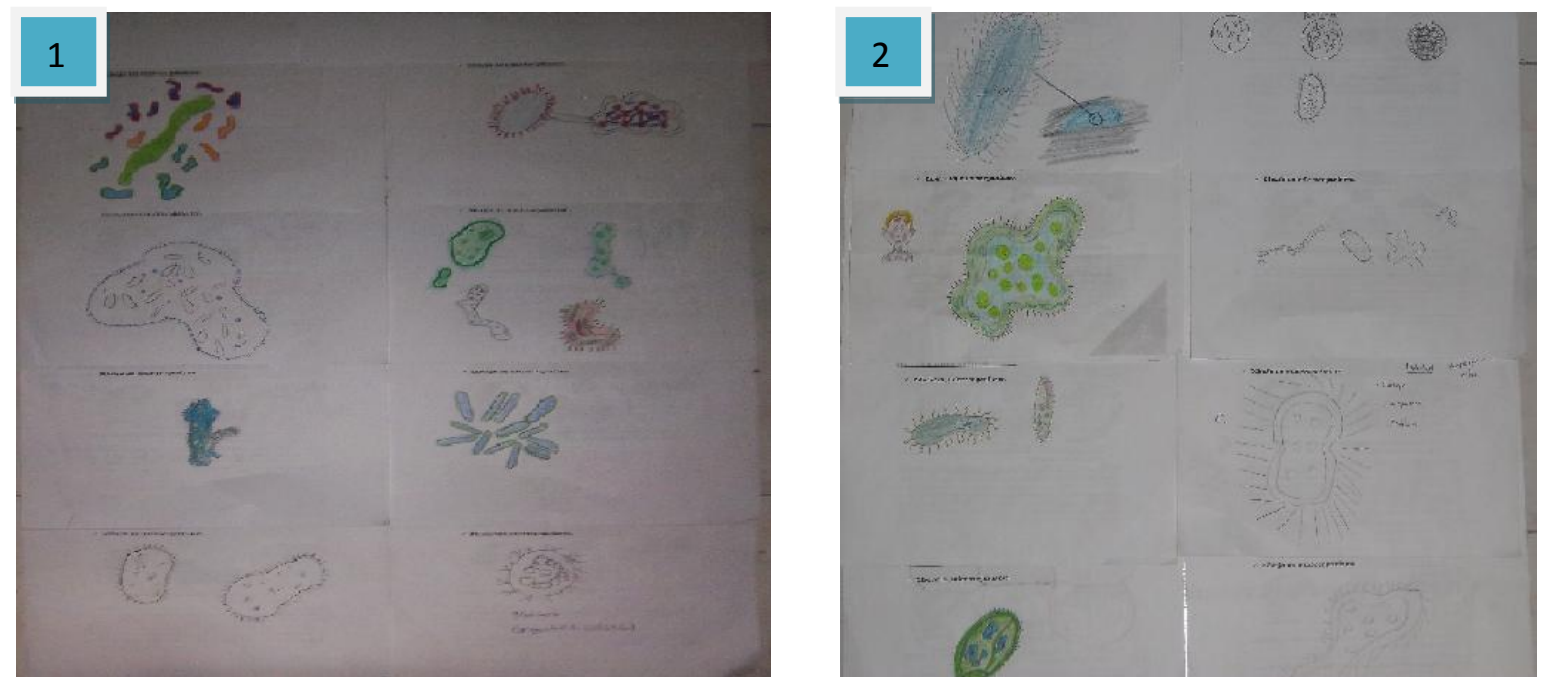

Fotografías tomadas por: Juan Carlos Rozo González

Respecto a los dibujos se puede observar que la mayoría tiene una comprensión de las diferentes formas que tienen los microorganismos, bacilos y espirilos, cabe resaltar que la mayoría de los estudiantes al pedir por el dibujo lo relacionaron de inmediato con la imagen que se plantea de la ameba, en casi un $90 \%$ de los dibujos se pudo evidenciar esta tendencia, muchos dibujaron una especie de vellosidad en la parte de la membrana de su organismo, le realizaron las diferentes partes que tienen las bacterias, donde se nota la incidencia que tiene el modelo de célula para dar su representación frente a lo que ellos consideran un microorganismo. En uno de los dibujos un estudiante pinto un rostro humano como si estuviera enfermo y lleno de bacterias, a partir de la imagen se puede inferir que este estudiante todavía relaciona a las bacterias como nocivas para la salud del ser humano. 


\section{TRABAJO PRÁCTICO"BUSCANDO EL MUNDO PERDIDO"}

En este T.P se diseñó una carrera de observación con el objetivo de reconocer la organización externa de los seres vivos y las interacciones que se dan a nivel macroscópico y microscópico en un ecosistema determinado. En este trabajo se elaboró una historia la cual fue contada por el investigador, donde los estudiantes debían encontrar diferentes organismos que se encontraban dispersos en todo el colegio, después de ello tenían que construir un ecosistema y plasmar las relaciones intraespecífica como interespecífica que se dan en las especies encontradas, luego de ello cada grupo; cabe resaltar que esta actividad practica se hizo cumpliendo el modelo de trabajo colaborativo, con el fin de que los estudiantes construyeran un conocimiento de forma colectiva, seguido a esto ya para finalizar el trabajo, cada equipo de trabajo debía exponer su ecosistema y a su vez decir todo lo que se encuentra en este incluyendo los factores bióticos y abióticos y sus respectivas relaciones. Las temáticas abordadas fueron:

$\checkmark$ Organización externa de los seres vivos.

$\checkmark$ Diversidad biológica y los factores abióticos que se encuentran en el ambiente.

$\checkmark$ Interacciones: (animal-suelo), (planta-microorganismo), (hongo-planta) (microorganismo-microorganismo) y (microorganismo-ser humano).

A continuación se presentan los resultados obtenidos en el trabajo práctico a partir de un registro fotográfico.

Ilustración 3, 4 y 5: fotografías que muestran los ecosistemas elaborados por los estudiantes de grado cuarto. En estas ilustraciones se muestran algunos de los ecosistemas más representativos elaborados por los estudiantes.
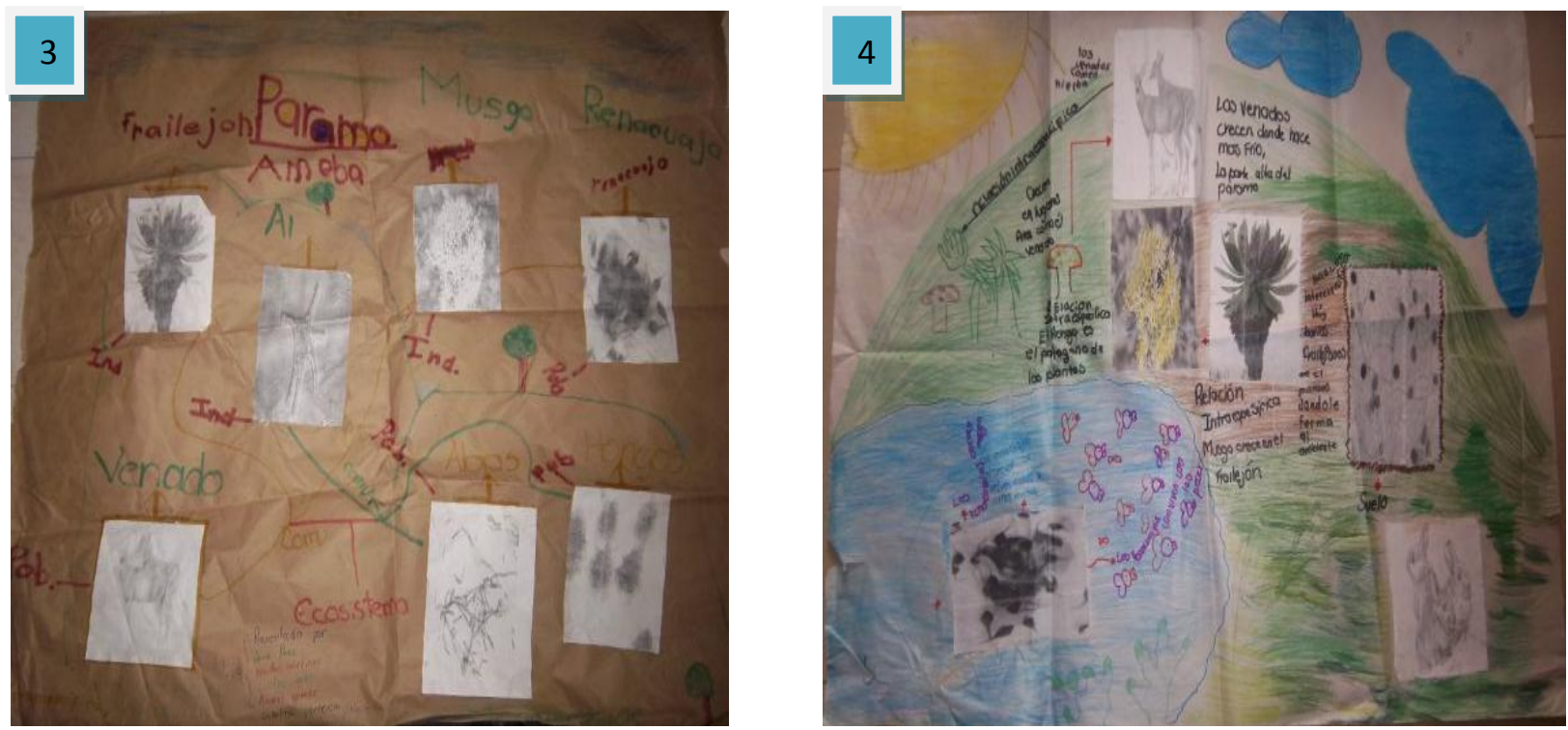


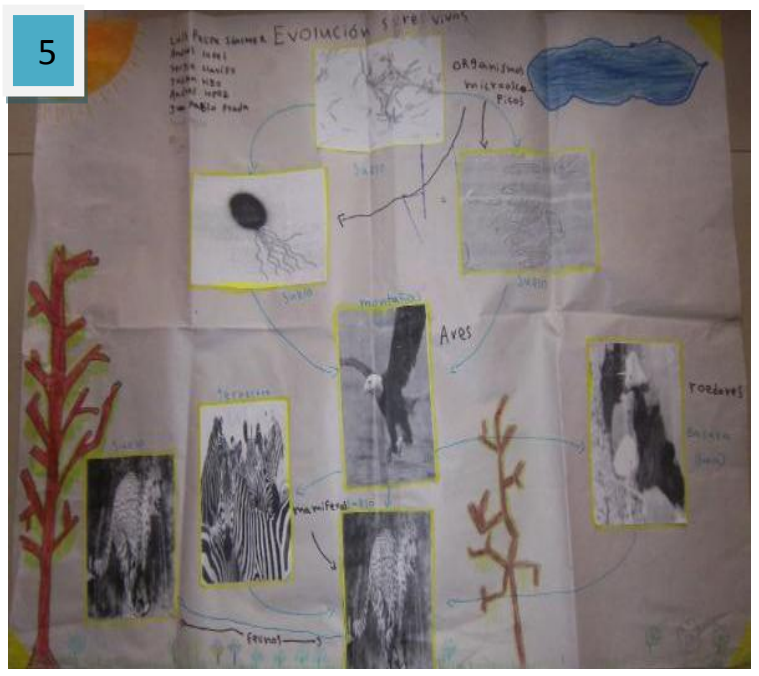

\section{Fotografías tomadas por: Juan Carlos Rozo González}

Las fotografías muestran los diferentes ecosistemas elaborados por los estudiantes, después de haber buscado cada organismo por todo el colegio, según las pistas dadas por el profesor, en estas imágenes los ecosistemas más representativos fueron el desierto y el páramo, se puede observar que los estudiantes entienden que hay una diversidad biológica no solo a nivel macroscópico sino también a nivel microscópico, en los ecosistemas se observa que los estudiantes ubicaron esos microorganismos en el suelo. A nivel de relaciones se puede observar que ellos lo que hacen es representar interacciones tanto intraespecífica como interespecífica que se dan entre los organismos por medio de las flechas dibujadas.

En la sustentación de la red trófica los estudiantes repetidamente explicaban que las bacterias presentan diferentes formas y colores, para poderlas observar se necesita del microscopio, dando a entender que si consideran que hay una diversidad microbiana en el suelo, de igual manera decían que estos organismos a nivel ecológico cumplen la función de descomponedores de materia orgánica, y que tanto ellos como otros organismos de diferentes especies necesitan uno del otro para poder vivir (mutualismo), ellos daban el ejemplo de las plantas donde decían que la planta para realizar fotosíntesis necesitaban de las bacterias para ayudar a captar alguna sustancia que la planta no pudiera lograr, y que la planta le brinda al microorganismos sea hongo o bacteria un fuente de alimentación.

La influencia de este trabajo práctico en los estudiantes fue de agrado y de motivación por aprender y utilizar sus habilidades motrices y mentales para el desarrollo de la misma, esta actividad permitió un desarrollo actitudinal, conceptual y procedimental; actitudinal porque el (T.P) se generó el espíritu de competencia sana, además se motivo al estudiante y la actividad lo hizo más participativo a diferencia de una clase tradicional (entendida como la explicación del maestro de un tema especifico de forma expositiva), a nivel procedimental se puede decir que el estudiante para llegar al resultado que fue la elaboración del ecosistema tenía que pasar por una serie de pasos, en primera instancia escuchar la historia, luego recibir las pistas para encontrar los organismos perdido, seguido a esto se procedió con la busca de los organismos 
por todo el colegio, para ello el debía saber a partir de la pista, el tipo de organismo que estaba en ese lugar especifico y no coger el de otro compañero, en este sentido también se puede mostrar un desarrollo de habilidades conceptuales. Por último complementado un poco más sobre el desarrollo conceptual se puede decir que se dió mediante la elaboración del ecosistema y de explicar sus características y las interacciones que se dan en este lugar, mediante una exposición la cual iba a ser su evaluación final tanto de la actividad como del periodo que estaba cursando el estudiante.

\section{DISCUSIÓN}

Los trabajos prácticos constituyen un ambiente de aprendizaje, donde se genera una construcción de explicaciones de un fenómeno natural o social que para el caso de este trabajo fue la diversidad y ecología microbiana, de igual manera conduce a la unión de varios lineamientos curriculares, la carrera de observación permitió una relación entre la biología, las artes y la educación física, de esta manera se puede entender que este tipo de trabajos ayuda a la interdisciplinariedad y entreteje los desarrollos conceptuales, procedimentales y actitudinales de los estudiantes de grado cuarto $\left(4^{\circ}\right)$ del colegio Champagnat de Bogotá.

El diseño de actividades prácticas deben tener una estructura, donde se debe tener en cuenta el papel que desempeña la observación, la pregunta, la teoría, los recursos y la interacción entre el maestro-estudiante para que así haya una construcción de conocimientos disciplinares, pedagógicos, epistemológicos, didácticos del contenido, del contexto y psicológicos.

Las actividades prácticas realizadas lograron en el estudiante la formulación de preguntas problema, conduciendo al sujeto para la solución de la misma, y por ende a un aprendizaje significativo evidenciado en la motivación por realizar dichas actividades y así mismo conocer las relaciones que tienen los microorganismos que habitan en el suelo con los demás organismos que hacen parte de un ecosistema.

\section{CONSIDERACIONES FINALES}

Los trabajos prácticos se pueden establecer como recursos que propician el aprendizaje significativo de los estudiantes no solo a nivel microbiológico sino también a nivel de otras áreas de conocimiento; de igual manera permiten el desarrollo de habilidades actitudinales, procedimentales y conceptuales en los estudiantes cumpliendo con uno de los objetivos planteados por los estándares básicos de la educación en Colombia.

El trabajo realizado permitió conocer la importancia y las interacciones de los microorganismos con el ambiente mediante el trabajo práctico "buscando el mundo perdido" donde los estudiantes lograron identificar el tipo de organismos que habitan en un ecosistema determinado (páramo, desierto y bosque) y a su vez explicar las dinámicas naturales que se presenta en este tipo de espacios. De igual manera identificaron que los microorganismos no solamente están asociados con 
enfermedades, y otros aspectos que perjudican al ser humano y a otros organismos sino que también intervienen en procesos como la digestión, la elaboración de antibióticos, la fermentación del yogurt, y la descomposición de materia orgánica en el suelo.

Las categorías de análisis e interpretación que surgieron a partir de los conocimientos que tienen los niños de cuarto de primaria sobre los microorganismos fueron: hábitat de los microorganismos, implicaciones que tienen los microorganismos sobre el ser humano, funciones vitales de los microorganismos, interacción bacteria-hombre y morfología de los microorganismos; lo anterior permitió una caracterización identificado por los estudiantes frente a los trabajos prácticos realizados por el investigador.

\section{AGRADECIMIENTOS}

A la línea de investigación biotecnología, Profesora Lola Constanza Melo, Colegio Champagnat de Bogotá, Profesora Floridiana, Profesor Luis Fernando Quijano, estudiantes de grado cuarto $\left(4^{\circ}\right)$.

\section{BIBLIOGRAFÍA}

- Aquiahualt, M \& Pérez, M. (2004). Manual de prácticas del laboratorio de microbiología general. Departamento de Biotecnología. Universidad Autónoma Metropolitana. México. D.F.

- Barberá, O \& Valdés, P. (1996). El trabajo práctico en la enseñanza de las ciencias: una revisión. En Universidad de Valencia (Ed.). Enseñanza de las ciencias. Departamento de didáctica de les ciencias de la Universidad de Valencia. (pp. 365379). Valencia. España.

- Brock, J. (2003). Biología de los microorganismos. 10ª edición en español. Pearson Educación S.A. Madrid.

- Caamaño, A. (2003). Los trabajos prácticos en ciencias. En: Jiménez, M. P. et al 2003. Enseñar ciencias. Editorial GRAO. Barcelona.

- Campbell, R. (1987). Ecología microbiana. Editorial LIMUSA. Ciudad de Mexico. México.

- Castro, M. \& Valbuena, E. (2007) ¿Qué biología enseñar y cómo hacerlo? Hacia una resignificación de la biología escolar. En Revista TE $\Delta$ Tecné, Episteme y Didaxis № 22. Universidad Pedagógica Nacional. Bogotá. Colombia.

- Del Carmen, L. (2000). Los trabajos prácticos. En: Perales Francisco Javier, Cañal de León, Pedro. Didáctica de las ciencias experimentales. Teoría y práctica de la enseñanza de las ciencias. Alcoi: Marfil.

- Díaz, F. \& Hernández, G. (1999). Estrategias docentes para un aprendizaje significativo, En Mc Graw Hill. (Ed.) Una interpretación constructivista, Constructivismo y aprendizaje significativo. (pp. 1-59). Editores Mc Graw Hill.

- Fonseca, G. (2010, octubre). Trabajos prácticos en la enseñanza de la biología. Charla presentada en el seminario de especialización en la enseñanza de la biología. Universidad Pedagógica Nacional. Bogotá. Colombia. 
- Galagovsky, L. (2004). Del aprendizaje significativo al aprendizaje sustentable. Parte 1: el modelo teórico. En Buenos Aires (Ed.) Enseñanza de las ciencias. (pp. 229240). Centro de Formación e Investigación en Enseñanza de las Ciencias Facultad de Ciencias Exactas y Naturales. Universidad de Buenos Aires Ciudad Universitaria. Buenos Aires. Argentina.

- Gutierrez, R. (1987). Psicología y aprendizaje de las ciencias. el modelo de Ausubel. En Madrid (Ed.). Enseñanza de las ciencias. (pp.118-128). Departamento de Didáctica de las Ciencias. Madrid. España.

- Hodson, D. (1994). Hacia un enfoque más crítico del trabajo de laboratorio. Investigación y experiencias didácticas. Enseñanza de las ciencias.

- Manacorda, A. \& Cuadros, D. (2005). Microbiología Ambiental. Buenos Aires. Argentina.

- Miguens, M. \& Garrett, R. (1991). Prácticas en la enseñanza de las ciencias. Problemas y posibilidades. Universidad de Bristol. School of Education. Enseñanza de las ciencias.

- Proyecto Político Pedagógico de la Universidad Pedagógica Nacional. Extraído el 16 de mayo de 2010 desde http: //www.pedagogica.edu.co.pdf.

- Sánchez, M. (2004). Microbiología de suelos, técnicas, métodos y medio de cultivo. Universidad autónoma de México.

- Torres, C. (1998). Estrategias y técnicas de investigación cualitativa. Facultad de ciencias sociales y humanas de UNAD. Bogotá, Colombia. 